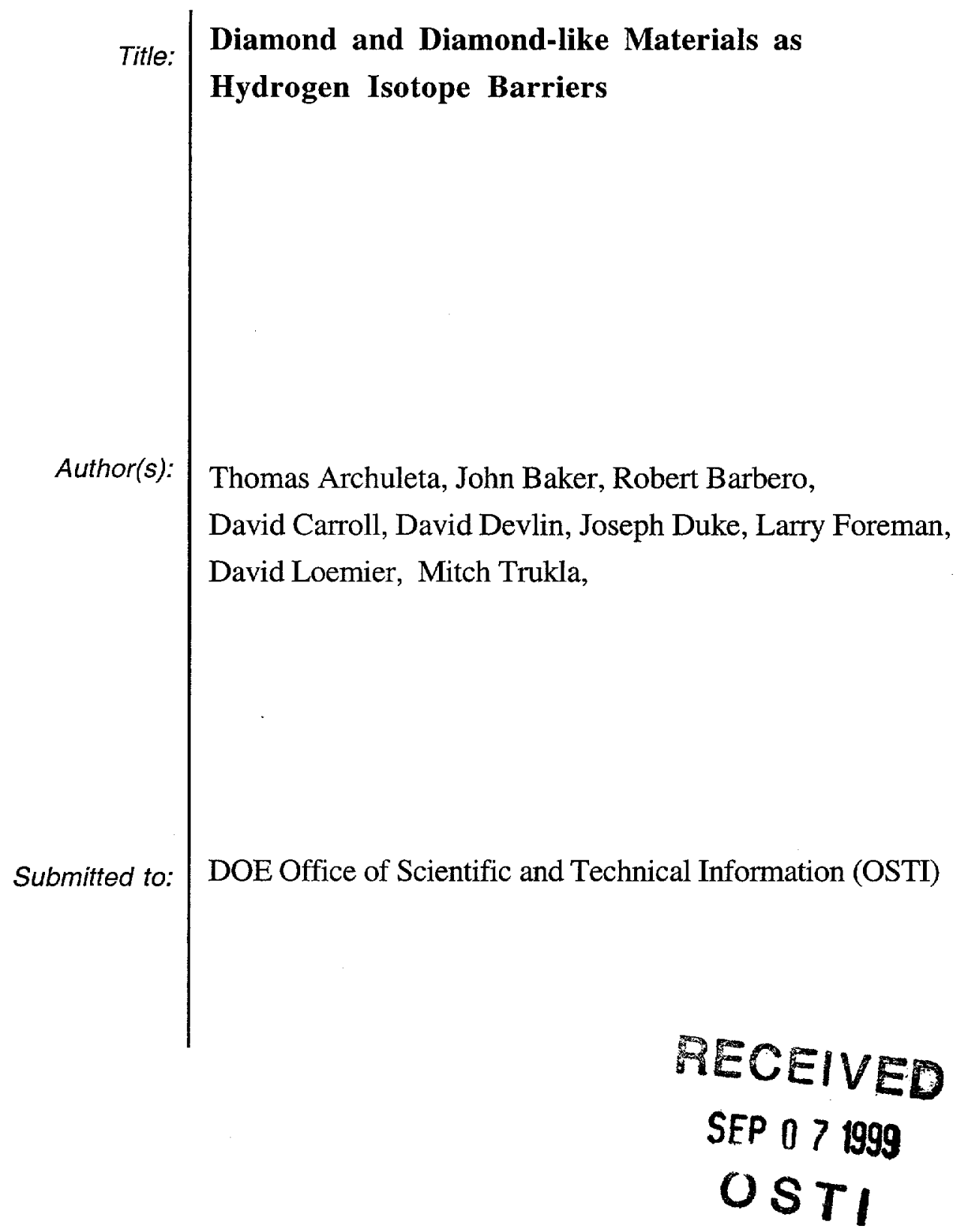

Los Alamos National Laboratory, an affirmative action/equal opportunity employer, is operated by the University of California for the U.S. Department of Energy under contract W-7405-ENG-36. By acceptance of this article, the publisher recognizes that the U.S. Government retains a nonexclusive, royaltyfree license to publish or reproduce the published form of this contribution, or to allow others to do so, for U.S. Government purposes. Los Alamos National Laboratory requests that the publisher identify this article as work performed under the auspices of the U.S. Department of Energy. Los Alamos National Laboratory strongly supports academic freedom and a researcher's right to publish; as an institution, however, the Laboratory does not endorse the viewpoint of a publication or guarantee its technical correctness. 


\section{DISCLAIMER}

This report was prepared as an account of work sponsored by an agency of the United States Government. Neither the United States Government nor any agency thereof, nor any of their employees, make any warranty, express or implied, or assumes any legal liability or responsibility for the accuracy, completeness, or usefulness of any information, apparatus, product, or process disciosed, or represents that its use would not infringe privately owned rights. Reference herein to any specific commercial product, process, or service by trade name, trademark, manufacturer, or otherwise does not necessarily constitute or imply its endorsement, recommendation, or favoring by the United States Government or any agency thereof. The views and opinions of authors expressed herein do not necessarily state or reflect those of the United States Government or any agency thereof. 


\section{DISCLAIMER}

Portions of this document may be illegible in electronic image products. Images are produced from the best available original document. 


\title{
Diamond and Diamond-like Materials as Hydrogen Isotope Barriers
}

\author{
Thomas Archuleta, John Baker, Robert Barbero, \\ David Carroll, David Devlin, Joseph Duke, *Larry Foreman, \\ David Loemier and Mitch Trukla
}

\begin{abstract}
This is the final report of a two-year, Laboratory Directed Research and Development (LDRD) project at Los Alamos National Laboratory (LANL). The purpose of this project was to develop diamond and diamond-like thin-films as hydrogen isotope permeation barriers. Hydrogen embrittlement limits the life of boost systems which otherwise might be increased to 25 years with a successful non-reactive barrier. Applications in tritium processing such as bottle filling processes, tritium recovery processes, and target filling processes could benefit from an effective barrier. Diamond-like films used for low permeability shells for ICF and HEDP targets were also investigated. Unacceptable high permeabilties for hydrogen were obtained for plasma-CVD diamond-like-carbon films.
\end{abstract}

\section{Background and Research Objectives}

Two forms of "diamond" were investigated in the project. The first is chemical vapor deposited (CVD) diamond. This is a polycrystalline, true diamond material that is deposited at elevated temperature. The material is overwhelmingly sp ${ }^{3}$ (diamond) bonded and contains little, if any, hydrogen. The second is diamond-like carbon (DLC). This material is deposited at low temperature. DLC is an amorphous, carbon-based material that shows a high hardness and low coefficient of friction (hence, the name diamond-like). It has mainly $\mathrm{sp}^{2}$ (graphitic) bonding with $\mathrm{sp}^{3}$ bonding to cross-link the graphitic part. DLC is a "tunable" material. By varying the hydrogen content and the processing, one can vary hardness, modulus, density, bandgap, and other properties, among them the permeability. The density ranges from 2 to $2.5 \mathrm{gm} / \mathrm{cc}$. CVD diamond was investigated as a long-term barrier material, while DLC was considered for the shell fabrication aspects of this project.

\footnotetext{
*Principal Investigator, e-mail: lforem@lanl.gov
} 
Diamond with its strong bonding and high density has significant potential as a hydrogen isotope barrier. Calculations have shown that diffusion of hydrogen in diamond occurs through bond centered interstitial $\mathrm{H}$ atom migration. Migration occurs through a transition state with calculated energy barrier of $1.9 \mathrm{eV}$ [1]. Experimental data on hydrogen diffusion in diamond is limited; however, one study reports a value of $2.4 \times 10^{-13} \mathrm{~cm}^{2} / \mathrm{s}$ at $860^{\circ} \mathrm{C}$ [2]. For comparison, the diffusion coefficient of hydrogen in iron at $860^{\circ} \mathrm{C}$ is $3 \times 10^{-4} \mathrm{~cm}^{2} / \mathrm{s}$, or nine orders of magnitude faster. The activation energy of hydrogen in iron is $0.04 \mathrm{eV}$; therefore the room temperature diffusion coefficient is still on the order of $10^{-4} \mathrm{~cm}^{2} / \mathrm{s}$. While no experimental studies yielding activation energies for hydrogen diffusion are available, if the energy barrier of $1.9 \mathrm{eV}$ is combined with the diffusion value at $860^{\circ} \mathrm{C}$, an estimated room temperature value of diffusion will be on the order of $10^{-20}$ $\mathrm{cm}^{2} / \mathrm{s}$.

Diamond does not chemisorb hydrogen significantly below $400^{\circ} \mathrm{C}$, and it is relatively inert to attack by atomic hydrogen. Thus, the absorption and dissociation of hydrogen prior to diffusion may be rate limiting at low temperatures. The relative inertness of diamond to hydrogen attack is important in limiting the formation of methane in applications where gas purity is important. The solubility of hydrogen in natural diamond is low; however, CVD diamond, as a consequence of processing, can contain significant concentrations of hydrogen. Proton nuclear-magnetic-resonance (NMR) measurements yield values in the range of 0.017 to 1.0 atomic percent. The hydrogen that is typically trapped during processing is strongly bound. Infrared (IR) measurements show C-H stretches in the 2850 to $3080 \mathrm{~cm}^{-1}$ range indicative of $\mathrm{sp}^{3}$ - and $\mathrm{sp}^{2}$-bound hydrogen. This hydrogen would not be expected to diffuse rapidly but exchange reactions with tritium could be of concern.

The data on hydrogen diffusion is limited to single-crystal material. The effect of high diffusivity paths such as grain boundaries and dislocations will be important. Variations in microstructure may have a significant effect on the performance of diamond films as barriers. We have no corresponding data on DLC materials. It was expected that permeability for these materials could potentially range from those similar to plasma polymers to that approaching diamond.

The processing of diamond by CVD is accomplished by a number of techniques involving the use of low concentration hydrocarbon precursors in a hydrogen plasma. The plasma, via abstraction by hydrogen radicals, forms the apparent methyl radical precursor. In addition, the atomic hydrogen preferentially etches graphitic carbon co-deposited during the process. Microwave plasmas are commonly used for diamond processing. A range of microstuctures can be evaluated to determine the effects of grain boundary diffusion. 
Current shell manufacturing processes begin with a polystyrene (PS) shell that is blown in a vertical furnace drop tower [3]. Because PS shells leak hydrogen in a matter of minutes, target capsules rely on a low permeability layer of poly (vinyl alcohol) (PVA). The PVA is deposited in a second drop tower process onto hand-selected polystyrene shells and gives the composite (PS+PVA) shells a half pressure time of about 40 hours for a deuterium fill. This time is short, but allows fabricators sufficient time to process the capsule into a target. Storing the target under deuterium pressure at dry ice temperatures insures that the target has a fuel charge when the target is shot. With a tritium fill, the situation is much worse; the half pressure time for shells of this type is only about 8 hours.

DLC has a number of properties that make it attractive as a shell material. First, it is relatively low- $Z$ (compared to glass, for instance) with a density close to aluminum; the ablation pressures this material would develop are currently unknown, but promising. Second, it is hard and smooth and unlikely to sustain damage in subsequent fabrication processes. Third, it is strong and should hold a substantial fuel charge. The proposed shells would be made by depositing the diamond shell material on a novel, depolymerizable mandrel. Depolymerizable shell mandrels can be fabricated from poly $(\alpha$-methylstyrene) (PAMS) using a controlled micro-encapsulation process. The process is ideally suited for mandrel shell production because it is rapid, cheap, and easily modified to change shell size. The process can produce up to 1200-3000 mandrel shells per hour. Shells with diameters of $400-1000 \mu \mathrm{m}$, wall thickness of 5-15 $\mu \mathrm{m}$, sphericities of $>99 \%$, and nonconcentricities of $<5 \%$ are obtained by this technique. Clean room, or at least clean bench, conditions must be maintained in the preparation of these shells.

\section{Importance to LANL's Science and Technology Base and National R\&D Needs}

The impact of these results will be far reaching. Applications for the weapons community are numerous. Hydrogen embrittlement limits the life of boost systems. The system's life could be increased to 25 years with a successful non-reactive barrier. Numerous applications in tritium processing at Savannah River and LANL could benefit from such a barrier. These include bottle filling processes, tritium recovery processes, target filling processes, and potential applications within the APT program. Diamond films for low permeability shells for inertial confinement fusion (ICF) targets has considerable promise. We expect, at the end of the first year, a clear demonstration of the effectiveness of diamond as a barrier and to seek support from the appropriate program offices for the areas mentioned above.

Benefits to the laboratory for science-based stockpile stewardship (SBSS) are the following: (1) These shells will support SBSS by enabling DT implosion experiments with 
low-Z ablators on the Nova and Omega lasers (DT experiments provide more fusion neutrons and better statistics) and, by extension, to targets for pulsed power facilities such as Atlas, Saturn, and PBFA. (2) The work supports SBSS by strengthening the fabrication capability at Los Alamos and puts us in position to supply DT-containing capsules that are easier to assemble and store. (3) Facilities such as Omega and PBFA II Z would be able to do experiments that they now cannot because of the tritium leakage of conventional shells. (4) This work would support efforts in the material science of diamond coating, a process that has strong commercial appeal. Note that it is not our intention to compete with GA for shell production; we will transfer this technology to them when the demand is high and the technology is mature. Los Alamos is in a unique position to develop the micro-encapsulation, PAMS chemistry, and diamond coating. These shells would have a tremendous impact on ICF; the technology would be in great demand. Los Alamos should be able to favorably exploit this development with DOE.

This coating process will be highly desirable to the chemical process industry in the area of caustic chemical production and use. Examples include ammonia production and any acid or base production or use. Hydrogen barriers at elevated temperature and pressure will be an important consideration in a hydrogen economy. Fuel cells operate at high temperatures and will be exposed to high concentrations of hydrogen. Fuel cell lifetime will be partly determined by the hydrogen protection of the cell. Also, such coatings applied to the inside of a gaseous or liquid hydrogen storage vessel would provide protection from hydrogen embittlement of the vessel, while possibly decreasing the weight to fuel ratio of the vessel.

The more fundamental aspects of hydrogen diffusion in CVD diamond will be of great interest to the electronics industry. Diamond has a significant potential as a wide bandgap semiconductor. Little is known about diffusion processes in diamond in general, and in particular hydrogen diffusion, which plays an important role in determining the properties of doped diamond. This information will be important to our current program investigating boron-doped CVD diamond for photocathode injectors at the Dual-Axis Radiographic Hydro-Test (DARHT) facility.

\section{Scientific Approach and Accomplishments}

A radio frequency, capacitively coupled, parallel plate discharge was used for the deposition of DLC. This is illustrated in Figure 1. The asymmetric arrangement of the cathode and anode combined with the difference in mobility of electrons vs. ions results in a self-bias across the plasma sheath. A voltage $(-500 \mathrm{~V})$ serves to accelerate ions from the plasma to the cathode or substrate. In our arrangement the vacuum chamber is grounded 
and serves as the anode. Methane gas is both dissociated and ionized to some extent within the plasma. The formation of DLC requires an ion bombardment effect. Ion bombardment sputters the more weakly bound sp 2 carbon leaving a high concentration of sp3 bonded carbon. If the voltage is too high, greater than $1000 \mathrm{~V}$ in our system, the ions are too energetic and tend to heat the material forming a glassy or graphitic carbon. If it is less than $100 \mathrm{~V}$, the film tends to be more polymeric and similar to glow discharge polymers (GDP) in properties.

Typical deposition conditions are given in Table I. Coatings were deposited on porous alumina substrates. These are commercially available membranes 60 microns thick with straight channels $200 \mathrm{~nm}$ in diameter. One side of the filter has a layer approximately $100 \mathrm{~nm}$ thick with $20 \mathrm{~nm}$ diameter pores. Figure 2 contains micrographs of the filter system showing a cross section and a plan view.

Table I. DLC Deposition Conditions

\begin{tabular}{|c|c|c|c|c|c|c|}
\hline . & $\begin{array}{c}\text { Coat ing } \\
\text { T hick ness } \\
\text { m ic rons }\end{array}$ & Gas & $\begin{array}{c}\text { Pressure } \\
\mathrm{Pa}\end{array}$ & $\begin{array}{l}\text { Power } \\
\text { watts }\end{array}$ & $\begin{array}{l}\text { Bias } \\
\text { Volts }\end{array}$ & $\begin{array}{l}\text { Deposit ion } \\
\text { Time min. }\end{array}$ \\
\hline Pret reat ment & $\ldots$ & $A r$ & 4.7 & 65 & -500 & 15 \\
\hline DLC coating & 2.3 & $\mathrm{CH}_{4}$ & 11.3 & 85 & -520 & 24 \\
\hline
\end{tabular}

The permeability measurements were performed by measuring the flow of hydrogen through the membrane, which is held in a stainless steel flange with O-rings and a metal frit for support. The system is illustrated in Figure 3. A fixed pressure of hydrogen is set at the upstream side and the downstream side is continuously pumped through a turbopump system maintaining a pressure below $10^{-5}$ Torr. The hydrogen is monitored under conditions of constant pumping speed with a mass spectrometer. The mass spectrometer signal is calibrated to a hydrogen flux. The calibration procedure makes use of a 40-micron pinhole from which hydrogen is leaked at a known pressure. The pinhole is in a symmetric arrangement with respect to the membrane to insure similar paths for the two fluxes. The flux through the pinhole is calculated by the well-known kinetic theory expression for the rate of effusion:

$$
\mathrm{J}=\frac{\mathrm{A} C(\Delta \mathrm{P})}{\sqrt{2 \pi \mathrm{MRT}}}
$$

where $\mathrm{A}$ is the cross sectional area of the pinhole and $\mathrm{C}$ is the Clausing factor. The flux is proportional to the pressure of hydrogen upstream. The ion signal from the mass 
spectrometer is also linear over the range of pressures investigated. A calibration constant can be obtained from the slope of the signal vs. pressure data and Equation 1.

Figure 4 shows the calibrated MS signal vs. pressure data for the pinhole, a $0.2-$ micron DLC film, and a 2.0-micron glow discharge polymer film (GDP). The permeabilities are $1.23 \times 10^{-10}$ and $2.26 \times 10^{-10} \mathrm{~cm}^{3}-\mathrm{cm} / \mathrm{cm}^{2}-\mathrm{s}-\mathrm{Pa}$ for DLC and GDP, respectively, calculated from the slopes of the plots and corrected for film thickness. While the DLC permeability is lower than the GDP, it is not a significant difference to warrant its use as a hydrogen barrier. The hydrogen permeability of PVA currently used to seal shells is six orders of magnitude lower than DLC. As might be expected, the two materials are similar in permeability. DLC can be considered a glow discharge polymer. While we have processed under conditions that lead to high elastic modulus and hard coatings, there may not be a significant difference in free volume between the two materials.

\section{Diamond Coatings}

Polycrystalline diamond was deposited on silicon wafers using a microwaveassisted chemical vapor deposition technique. The system is illustrated in Figure 5 and consists of a 1.5-kW microwave generator magnetron with wave guides and coupling system. The symmetric coupler produces a spherical plasma within the chamber or cavity. The sample is held below the plasma on a motorized heating stage. A bias of $-100 \mathrm{~V}$ can be applied to the substrate. A typical deposition involves a hydrogen plasma pretreatment of the wafer at a pressure of 40 Torr and $800^{\circ} \mathrm{C}$, followed by a nucleation step that requires a -100 volt bias on the substrate. The plasma consists of $10 \%$ methane and a balance of hydrogen at 40 Torr pressure and $900^{\circ} \mathrm{C}$. The final diamond growth conditions are $900^{\circ} \mathrm{C}$, $1 \%$ methane, and the balance of hydrogen at 40 Torr. A micrograph of a typical film is shown in Figure 6.

A hole $0.5 \mathrm{~cm}$ in diameter was etched from the back side of the wafer using a mixed acid. This left a region of diamond free for permeation studies. Complete removal of the silicon wafer to produce free-standing films was not possible for films as thin as 2.0 microns. Excessive residual stress in the film resulted in fracture. The etched silicon/diamond membrane was mounted in the permeation apparatus previously described; however, the diamond films were instead glued to a $1 / 2$-diameter tube with a high vacuum, low vapor pressure epoxy. Tests were performed but no hydrogen flux was detectable. The permeability is apparently less than $10^{-13} \mathrm{~cm}^{3}-\mathrm{cm} / \mathrm{cm}^{2}-\mathrm{s}-\mathrm{Pa}$, which is an estimate of the lower limit of our detectability with this system and a 2.0-micron-thick diamond film. To obtain a higher permeability and a measurable quantity of hydrogen, elevated temperatures and high pressures need to be employed. A high-pressure, high-temperature permeation system was constructed and developed at the Tritium Systems Test Assembly (TSTA) for 
this purpose, but due to delays in obtaining calibration gases, to date no measurements have been conducted.

\section{Discussion}

The results of tests performed on DLC suggest that this particular form of DLC does not make a good hydrogen barrier. It is known that DLC can contain a significant amount of hydrogen, both bonded and nonbonded [4], which could provide a potential mechanism for rapid hydrogen diffusion via hopping mechanisms. The value for the permeability is similar to GDP. This may not be surprising in that the GDP and DLC

processes are very similar. The main difference is the use of a bias and ion bombardment in the DLC process. This is expected to produce a larger percentage of $\mathrm{sp} 3$ carbon bonding; however, a significant amount of the material may be structurally very similar to the GDP material.

While the diamond material may yet make a good hydrogen barrier, there are some practical aspects concerning its application that need to be considered. First, the processing is difficult requiring intense plasmas and high temperatures. Methods for coating the inside of tubes, for example, have not been developed. Also, issues concerning adhesion of films to materials such as stainless steel exist. The strong affinity of iron for carbon makes it impossible to deposit directly on steel, and an intermediate barrier layer is required. We have proposed the use of an iron aluminide as an intermediate layer for this purpose. This can be fabricated by a number of commercial processes, which includes coating steel with aluminum and heat treating to form an aluminide layer. Other possible intermediate layers include TiC and TiN [5]. Diamond can be nucleated on these materials as well; however, the aluminide and the TiC and TiN are very good diffusion barriers themselves. It has been shown that the permeation rate for tritium through stainless steel can be reduced 5 orders of magnitude by coating with either TiC or TiN. FeAl coatings can result in 3 orders of magnitude reduction in permeation rates. It is suggested these coatings would be better candidates for barrier materials and warrant further investigation. 


\section{References}

[1]. Mehandru, S.P.; Anderson, A.B.; Angus, J.C.; "Hydrogen binding and diffusion in diamond," J. Mater. Res 73, 689-95 (1992).

[2]. Popvic, G; Wilson,R.G.; Sung, T.; Prelas, M. A.; Khasawinah. S.; "Diffusion of boron, lithium, oxygen, hydrogen, and nitrogen in type IIa natural diamond," J Appl.

Phys. 77, (10), 5103-6 (1995).

[3]. Burnham,A.K.; Grens , J.Z.; Lilley, E. M.; "Fabrication of polyvinyl alcohol coated polystyrene shells," J. Vac. Sci. Technol. A,Vol. 5, No. 6 (1987).

[4]. Martinu, A.; Raveh, D, Boutard, S.; Houle, D.; Poitras, N, V.;Wertheimer, M.R. "Properties and stability of diamond-like carbon films related to bonded and unbonded hydrogen."

[5]. Hollenberg, G.W.; Simonen, E.P.; Kalinin G.; Terlain, A.; "Tritium.hydrogen barrier development," Fusion Engineering and Design 28, 190-208 (1995). 


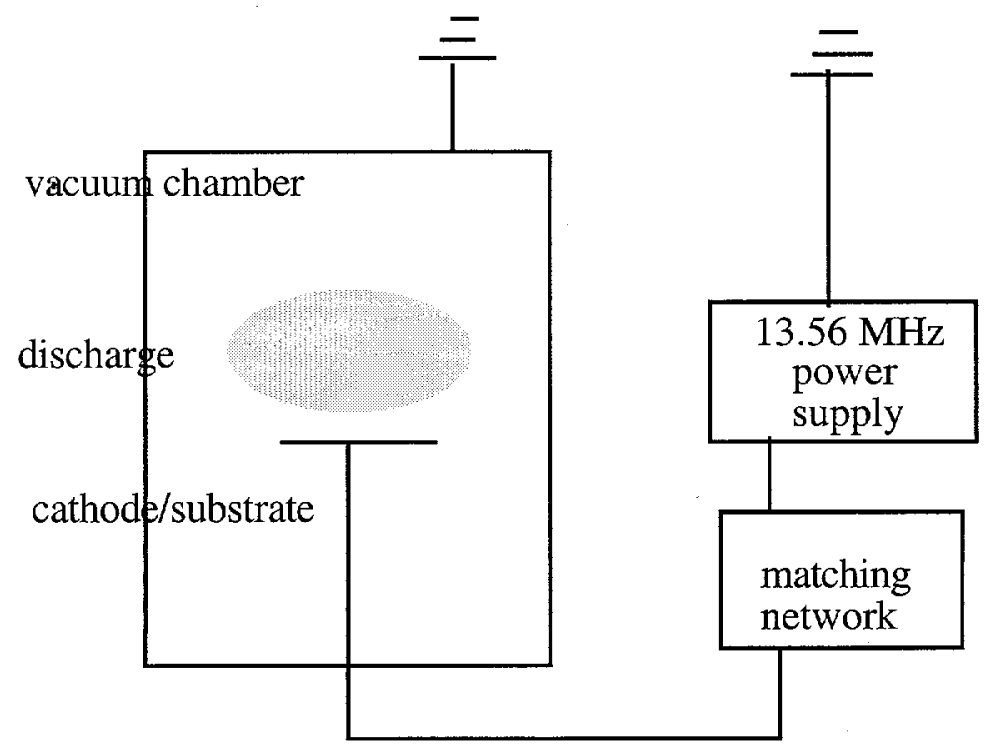

Figure 1. Schematic of the plasma deposition process for DLC.
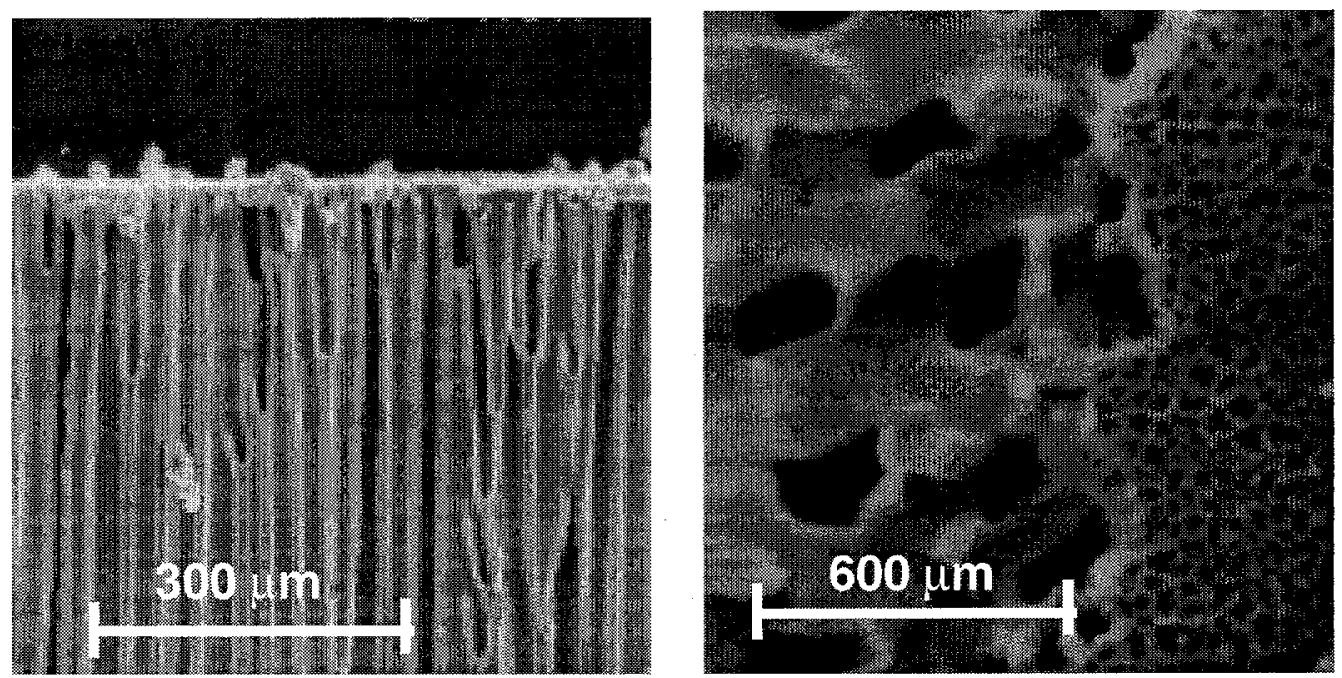

Figure 2. Micrographs of the porous alumina substrate used to support the DLC films. 


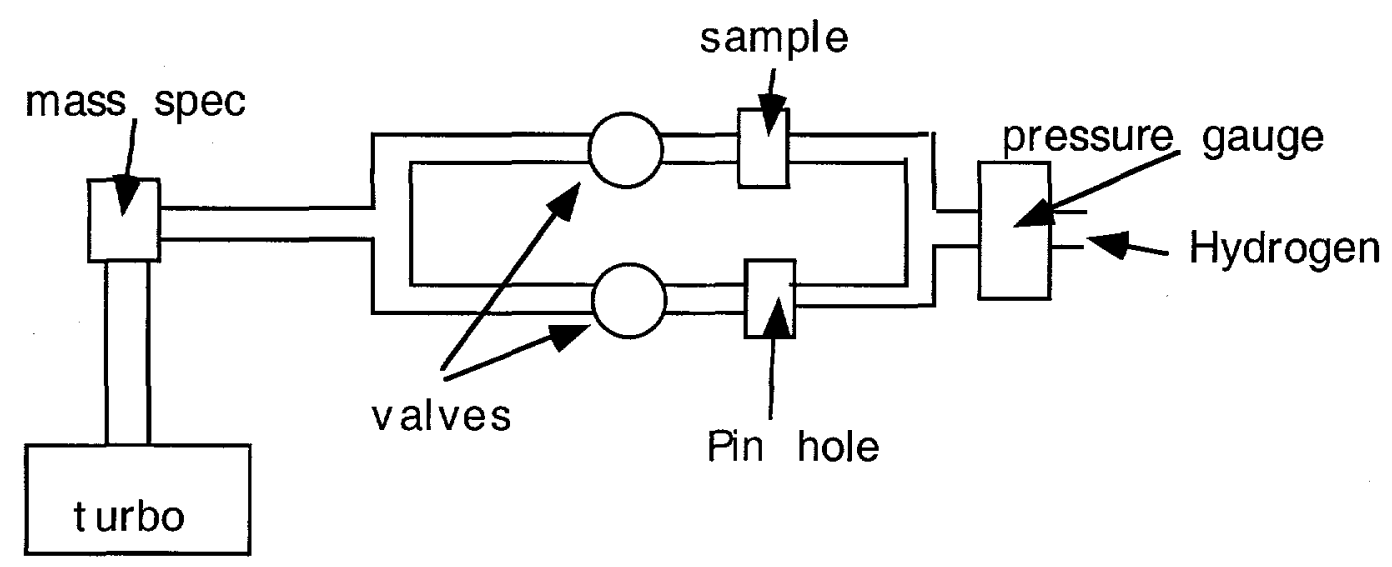

Figure 3. Schematic of the mass spectrometer setup used for measuring hydrogen permeation. 


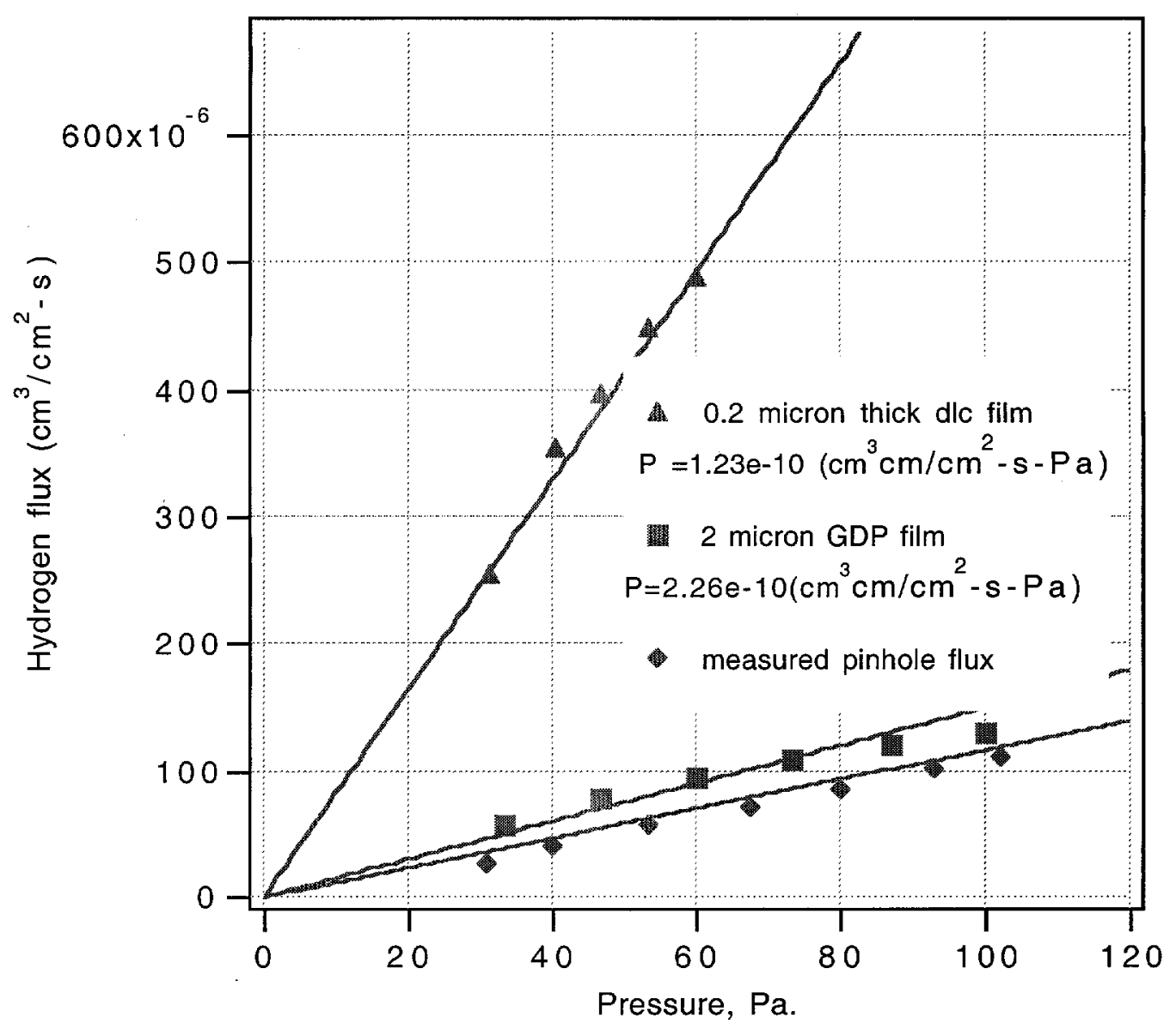

Figure 4. Hydrogen flux measurements through DLC and GDP films. The permeabilities are $1.23 \times 10^{-10}$ and $2.26 \times 10^{-10} \mathrm{~cm}^{3}-\mathrm{cm} / \mathrm{cm}^{2}-\mathrm{s}-\mathrm{Pa}$, respectively. 


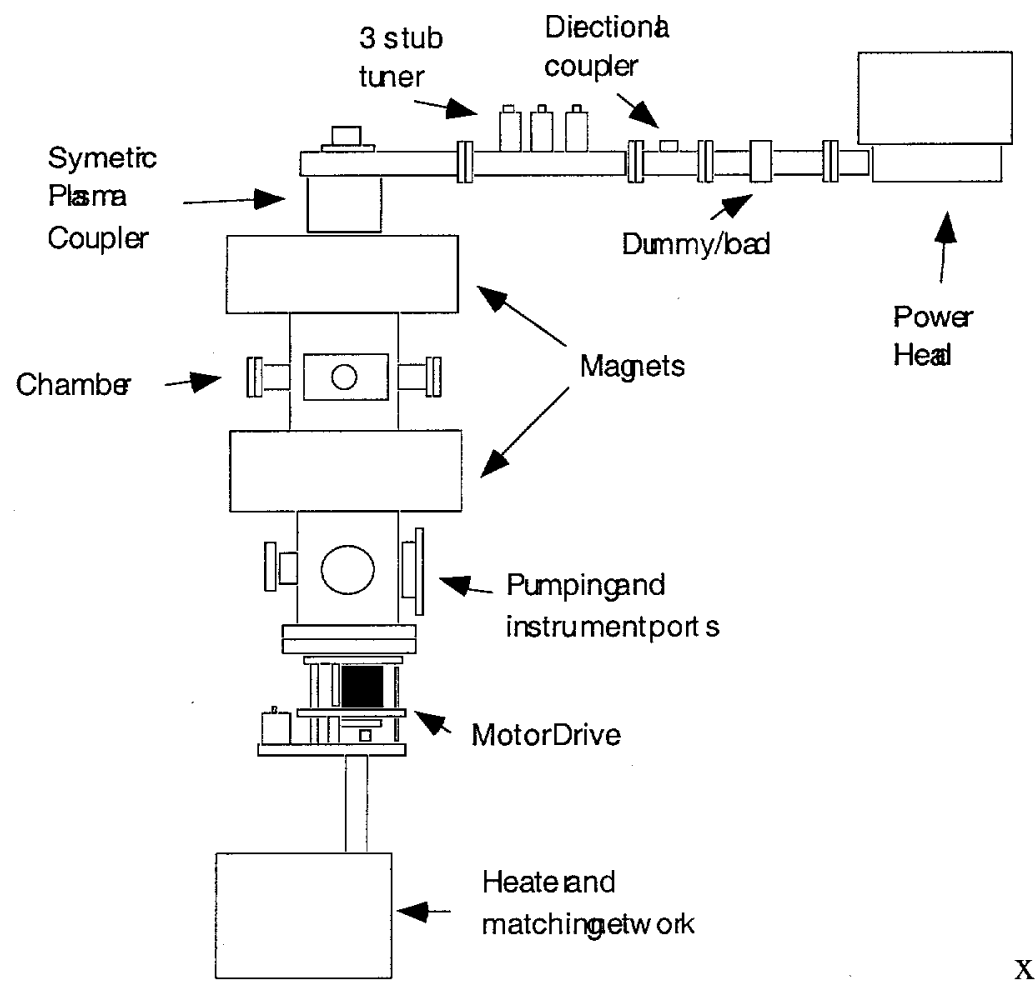

Figure 5. Microwave assisted chemical vapor deposition system for depositing diamond films.

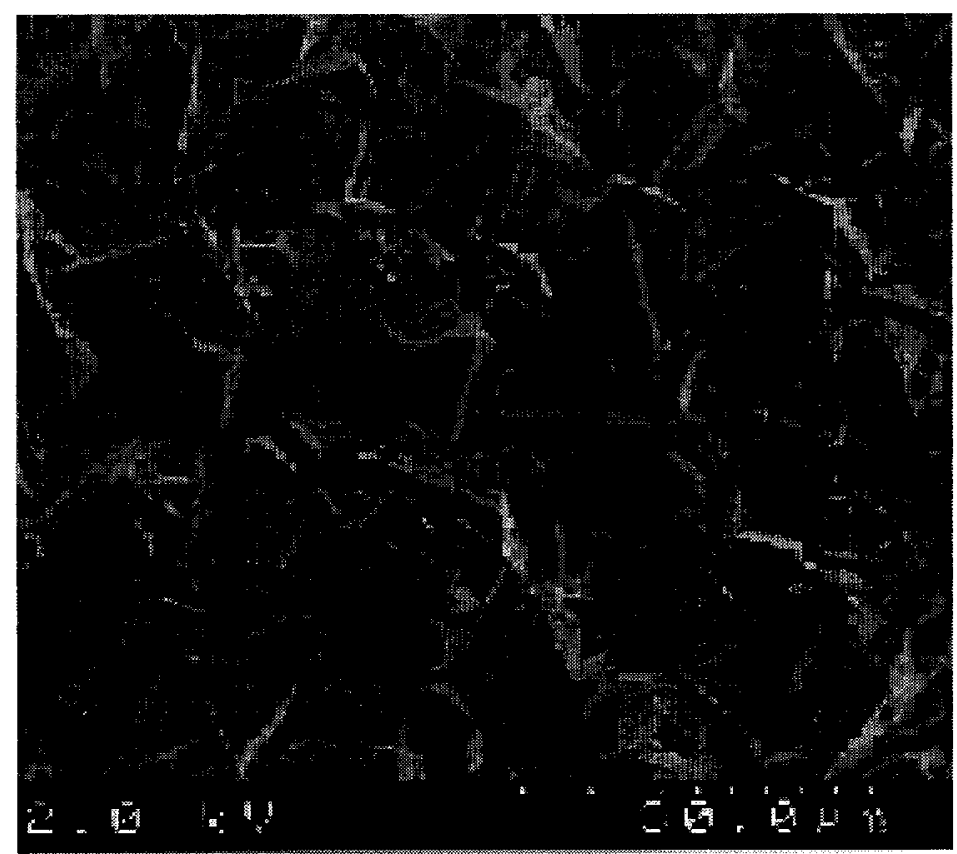

Figure 6. Micrograph of CVD diamond film used in permeation studies. 